\title{
Severe Allergic Reaction Caused by Pre-Operative Somatostatin Analog Treatment of Tsh- and Gh- Secreting Pituitary Adenoma: A Case Report
}

\author{
Chuyue $\mathrm{Wu}^{1}$, Feng Gu${ }^{1 *}$, Xuejing Cong ${ }^{2}$, Jun $\mathrm{Li}^{2}$ and $\mathrm{Xu} \mathrm{Li}^{2}$ \\ ${ }^{1}$ Clinic of China Guss Medical Group, Peking Union Medical College Hospital, China \\ ${ }^{2}$ Clinic of China Guss Medical Group, China
}

*Corresponding author: Feng Gu, Clinic of China Guss Medical Group, Peking Union Medical College Hospital, China.

To Cite This Article: Chuyue Wu, Feng Gu, Xuejing Cong, Jun Li, Xu Li, Severe Allergic Reaction Caused by Pre-Operative Somatostatin Analog Treatment of Tsh- and Gh-Secreting Pituitary Adenoma: A Case Report. Am J Biomed Sci \& Res. 2019 - 6(4). AJBSR.MS.ID.001053. DOI: 10.34297/ AJBSR.2019.06.001053.

Received: 浅 November 09, 2019; Published: 非 December 03, 2019

\begin{abstract}
TSH-and GH-secreting pituitary adenomas are rare and account for fewer than 1\% [1,2]. Nowadays, neurosurgery is still considered to be the first-line therapy for this kind of tumor [3]. In the meanwhile, pre-operative medical therapy with somatostatin analogues (SSA) is increasingly used and considered highly effective in reducing thyroid-stimulating hormone (TSH) and growth hormone (GH) secretion [4]. This report described a rare case of a TSH/GH co-secreting pituitary adenoma, which was initially noted as atrial fibrillation and heart failure. During the period of pre-operative therapy with SSA, the patient was affected by rare side effects, hyperthermia and pancytopenia, which was deemed to be a kind of allergic reaction. Then the patient took a transsphenoidal resection of the tumor. After the surgery, he was treated with radiotherapy, followed by methimazole and dopamine agonists. Finally, his thyroid function fell back to normal, as well as his GH, insulin-like growth factor 1 (IGF-1) and complete blood count (CBC). In summary, this patient had a rare and severe adverse reaction with the treatment of SSA and a serious risk of undergoing surgery due to the cardiac complications. Fortunately, the patient's disease was finally well controlled through rigorous preoperative preparation, successful neurosurgery and postoperative radiotherapy followed by medical therapy, which should be attributed to the multidisciplinary collaboration.
\end{abstract}

\section{Case Presentation}

A 48-year-old man complained heat intolerance, palpitations and excessive sweat in 2008, which he did not care too much. In 2012, he complained of chest tightness, shortness of breath after activities, and lower extremity edema. Gradually he cannot be supine at night. Then the patient was referred to cardiology department for evaluation, diagnosis with atrial fibrillation and heart failure, treatment with digoxin, spironolactone, beta blocker, warfarin, etc. Considering the symptoms and the heart problems, thyroid function tests were conducted and revealed a TSH of 4.085 $\mu \mathrm{IU} / \mathrm{ml}$ (normal range: 0.38-4.34). Free T3 and free T4 were 6.75 $\mathrm{pg} / \mathrm{ml}$ (normal range: $1.8-4.1$ ) and $4.73 \mathrm{ng} / \mathrm{dl}$ (normal range: 0.81 1.89) respectively. Total $\mathrm{T} 3$ and total $\mathrm{T} 4$ increased accordingly. He was subsequently referred to endocrinology for abnormal thyroid function. Upon examination, the patient was noted to have coarse facial features, skin thickening and enlargement of his hands and feet. He also reported a dysfunction of sex. On review of symptoms, he denied headaches or any recent vision loss. He did not have exophthalmus. He had no significant medical history. His height was
$166 \mathrm{~cm}$ and weight was $62 \mathrm{~kg}$. His heart rate was $90 \mathrm{bpm}$ irregularly and blood pressure was $120 / 72 \mathrm{mmHg}$.

Due to a suspicion for acromegaly, we checked growth hormone elevated at $22.9 \mathrm{ng} / \mathrm{ml}$ (normal range: 0.03-10.00). Oral glucose tolerance test (OGTT) showed the lowest level of GH was $16.7 \mathrm{ng} /$ $\mathrm{ml}$, failed to be suppressed below $1 \mathrm{ng} / \mathrm{ml}$. IGF-1 was $214 \mathrm{ng} / \mathrm{ml}$ (normal range for age: 94-252). Other pituitary function was also assessed (Table 1). Furthermore, the patient was also noted to have severe sleep apnea and impaired glucose tolerance. The formal visual field test showed a visual field defect at the under peripheral of the left eye. MRI of pituitary revealed a macroadenoma (maximal diameter 23mm) (Figure 1). A thyroid ultrasound demonstrated a goiter and multiple solid cystic nodules. In addition, the complete blood count at admission revealed white blood cells $3.32 * 109 / \mathrm{L}$, neutrophil 1.81*109/L, hemoglobin $92 \mathrm{~g} / \mathrm{L}$, and platelet 93*109/L. We thought that might be related to hyperthyroidism or hypersplenism resulted from the right heart failure. 

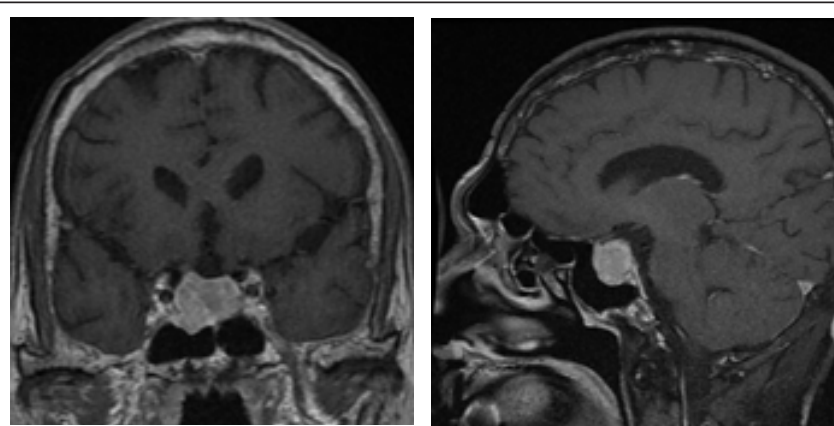

Figure 1: Preoperative T1-weighted coronal and sagittal MRI showing a heterogeneously enhancing $2.3 \mathrm{~cm}^{\star} 2.2 \mathrm{~cm}^{*} 2.1 \mathrm{~cm}$ mass in the sella.

Table 1: Pituitary and thyroid hormonal profile at presentation.

\begin{tabular}{|c|c|c|}
\hline Test & Value & Normal range \\
\hline TSH & 4.085 & $1.38-4.34 \mu \mathrm{pg} / \mathrm{ml} / \mathrm{ml}$ \\
\hline FT3 & 6.75 & $0.81-1.89 \mathrm{ng} / \mathrm{dl}$ \\
\hline FT4 & 4.73 & $0.66-1.92 \mathrm{ng} / \mathrm{ml}$ \\
\hline TT3 & 2.33 & $4.3-12.5 \mathrm{ug} / \mathrm{dl}$ \\
\hline TT4 & 19.93 & $0.03-10.00 \mathrm{ng} / \mathrm{ml}$ \\
\hline GH (basal) & 22.9 & $<1 \mathrm{ng} / \mathrm{ml}$ \\
\hline GH (OGTT) & 16.7 & $94-252 \mathrm{ng} / \mathrm{ml}$ \\
\hline IGF-1 & 214 & $2.64-13.13 \mathrm{ng} / \mathrm{ml}$ \\
\hline Prolactin & 1.9 & $4.0-22.3 \mu \mathrm{gg} / \mathrm{dl}$ \\
\hline Cortisol (8am) & 9.65 & $<46 \mathrm{pg} / \mathrm{ml}$ \\
\hline ACTH (8am) & 63 & $\mathrm{ug}$ \\
\hline 24h urine cortisol & 68 & $\mathrm{mIU} / \mathrm{ml}$ \\
\hline FSH & 12 & $\mathrm{mIU} / \mathrm{ml}$ \\
\hline LH & 7.3 & \\
\hline
\end{tabular}

We did the octreotide inhibition test that a decrease of $43.5 \%$ in TSH and 61\% in GH were observed (Table 2). To control thyroid hormone and GH hypersecretion and to reduce the risk of surgery, a period of 4 months' therapy with pre-operative SSA was carried out, which began in January 2013. We gave the patient lanreotide $40 \mathrm{mg}$ for five times then octreotide LAR 20mg twice. During the period, the patient was intermittently observed high heat above 39-42 Celsius degree, just after the injection of SSA. Due to a suspicion for being allergic to SSA, the patient was treated with dexamethasone that intended to keep temperature normal. Unfortunately, after the SSA therapy, the thyroid function was still abnormal, and the tumor size did not significantly reduce (the mass size from $23 * 22 * 21 \mathrm{~mm}$ to $25^{*} 18^{*} 21 \mathrm{~mm}$ ). On June 15 th, 2013 , the patient was treated with octreotide again, which caused his pancytopenia getting worse (Table 3). We prescribed granulocyte colony-stimulating factor (G-CSF) and prednisone (from $45 \mathrm{mg}$ qd to $15 \mathrm{mg}$ qd within one month) to deal with that. After multidisciplinary discussion, a week later after another injection of lanreotide, our patient proceeded to transsphenoidal resection of the macroadenoma on August 1st, 2013. Immunohistochemical staining of the adenoma appearances that GH, TSH and prolactin (PRL) were positive, while adrenocorticotropic hormone (ACTH), follicle-stimulating hormone (FSH) and luteinizing hormone (LH) were negative (Figure 2).

Table 2: Octreotide inhibition test: hypodermic injection of octreotide $0.1 \mathrm{mg}$ twice at $0 \mathrm{~h}$ and $8 \mathrm{~h}$, respectively.

\begin{tabular}{|c|c|c|c|c|c|c|c|c|}
\hline Time & $\mathbf{0 h}$ & $\mathbf{2 h}$ & $\mathbf{4 h}$ & $\mathbf{6 h}$ & $\mathbf{8 h}$ & $\mathbf{1 2 h}$ & $\mathbf{2 4 h}$ & Inhibition Rate \\
\hline $\mathrm{TSH}(\mu \mathrm{IU} / \mathrm{ml})$ & 3.729 & 3.069 & 2.446 & 2.378 & 2.229 & 2.294 & 2.107 & $43.50 \%$ \\
\hline $\mathrm{GH}(\mathrm{ng} / \mathrm{ml})$ & 17.8 & 7.62 & 6.95 & 9.51 & 12.6 & 10.4 & --- & $61.00 \%$ \\
\hline
\end{tabular}

Table 3: The treatment of patient's pancytopenia during the therapy of SSA preoperatively.

\begin{tabular}{|c|c|c|c|c|c|}
\hline Date & WBC (x109/L) (4.0-10.0) & NEUT (x109/L) (2.0-7.5) & HGB (g/L)(120-160) & PLT(x109/L) (100-300) & Medicine \\
\hline $09-06-13$ & 3.73 & 2.23 & 144 & 90 & \\
\hline $18-06-13$ & 2.55 & 1.43 & 115 & 72 & $6-15$ octreotide \\
\hline
\end{tabular}




\begin{tabular}{|c|c|c|c|c|c|}
\hline $28-06-13$ & 8.22 & 6.82 & 120 & 71 & $6-27$ G-CSF \\
\hline $01-07-13$ & 1.93 & 1.11 & 114 & 68 & Pred $45 \mathrm{mg}$ \\
\hline $05-07-13$ & 5.59 & 4.55 & 126 & 94 & Pred 35mg \\
\hline $08-07-13$ & 3.15 & 2.3 & 119 & 64 & Pred 30mg \\
\hline $14-07-13$ & 4.39 & 3.29 & 129 & 84 & Pred $25 \mathrm{mg}$ \\
\hline $23-07-13$ & 3.73 & 2.26 & 144 & 12 & Pred $15 \mathrm{mg}$ \\
\hline $30-07-13$ & 4.41 & 2.88 & 148 & 67 & $07-25$ lanreotide \\
\hline
\end{tabular}

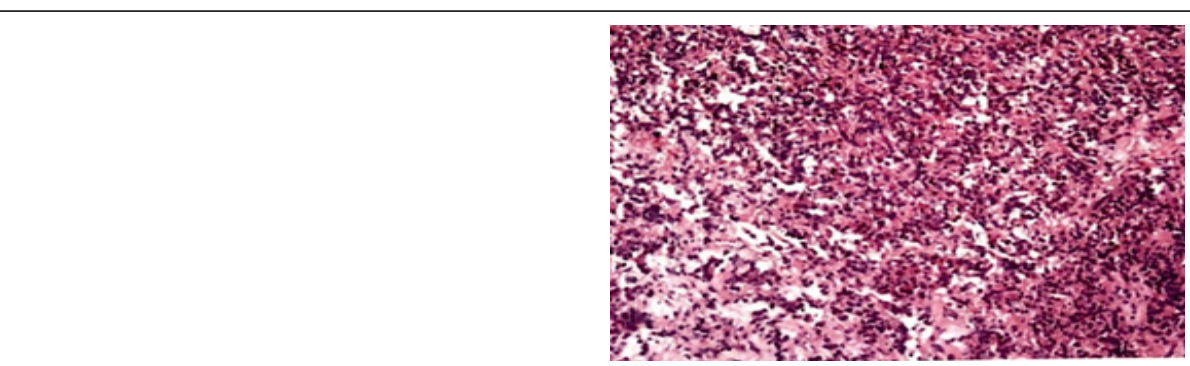

Figure 2: Higher power micrograph of the patient's pituitary adenoma. Micrographs of Xiaoyan Chang and Yancai Liu, Department of Pathology, Peking Union Medical University Hospital.

One month after the surgery, the hyperthyroidism was recurrence without an evidence of tumor recurrence from pituitary imaging. We had a multidisciplinary discussion again and decided to treat the patient with radiotherapy, which proceeded from 18th September to 22nd October in 2013. However, two months of post operatively, patient's thyroid function still did not return to normal.

The next four years after surgery and radiotherapy, the patient took methimazole initially whereas the efficacy was poor.
Considering of his severe side effect to SSA and his abnormal thyroid function, we tried the treatment with dopamine agonists, bromocriptine $(2.5 \mathrm{mg}$ tid to $7.5 \mathrm{mg}$ tid) and subsequently cabergoline ( $3 \mathrm{mg}$ qw to $2 \mathrm{mg}$ qw). Gradually, the patient's thyroid function fell back to normal, so did his GH, IGF-1 and CBC.

In September 2017, repeat MRI demonstrated no tumor recurrence (Figure 3). In March 2018, the examination of thyroid function, GH, IGF-1 and CBC were all normal.
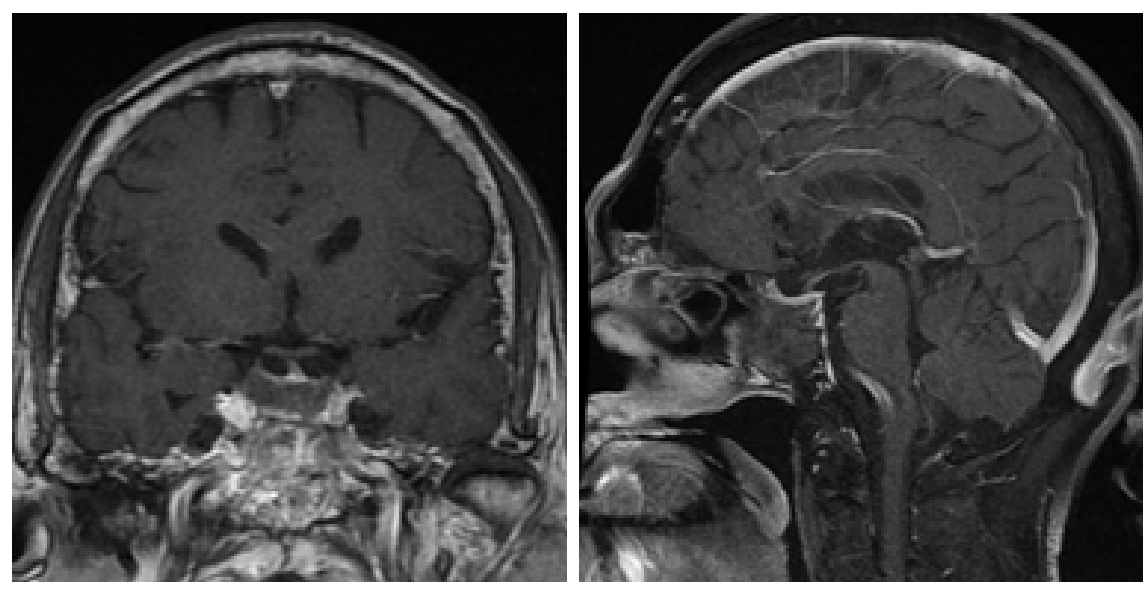

Figure 3: T1-weighted coronal and sagittal MRI done 4 years after surgery.

\section{Discussion}

TSH- and GH- secreting pituitary adenomas are rare and account for fewer than $1 \%$ of all pituitary adenomas. Our patient was initially noted with atrial fibrillation and cardiac decompensation, which was associated with poorly controlled hyperthyroidism [5]. It is rare that TSH secreting pituitary adenoma leads to severe heart problems. But it is important to check a pituitary cause of hyperthyroidism when the thyroid function shows elevated free T4 and/or T3 levels with a normal or unsuppressed TSH, because if we misdiagnosed as primary hyperthyroidism or mistreated with antithyroid drugs or thyroidectomy, the clinical symptoms would get worse [6]. Early diagnosis and treatment of TSH-secreting adenomas is critical in avoiding the neurological and endocrine complications [7].

The first-line treatment of TSH and GH-secreting pituitary adenomas is surgical resection. Pre-operative medical therapy with somatostatin analogues (SSA) can reduce tumor size and control thyroid hormone and $\mathrm{GH}$ hypersecretion, which is important to 
reduce the risk of surgery and perioperative thyroid crisis [8]. Pre-operative SSA treatment utilized to normalize GH and IGF1 levels and reduce the tumor size [9]. Overall, octreotide and lanreotide are first-generation SSA and are effective in $90 \%$ of patients with TSH-secreting adenoma and 20\%-70\% of patients with acromegaly [10]. However, there seemed little efficacy in our patient with octreotide and lanreotide. Kazuhiko [11] suggested that the expression levels of the specific subtypes of somatostatin receptors (sstr) mRNAs of TSH-secreting adenoma may be related to the efficacy of treatment with SSA. Their findings demonstrated that TSH-secreting adenomas express sstr2A predominantly, the expression level of sstr5 mRNA may be a factor affecting the tumor shrinkage by SSA against TSH-secreting adenomas. Additionally, pasireotide (SOM230), as a novel multireceptor-targeted SSA [10], and pegvisomant, a growth hormone receptor antagonist, may offer the potential for efficacious disease control [12].

The most common adverse effect of SSA is gastrointestinal symptoms, like constipation, flatulence, diarrhea, nausea and abdominal pain. By inhibiting cholecystokinin secretion, SSA also can lead to gallbladder sludge and gallstones. Other rare side effects include injection-site erythema, pernicious anemia related to vitaminB12 deficiency, and blood glucose problem [13]. However, our patient occurred hyperthermia and pancytopenia, which seemed like a kind of allergic reaction, just after every injection of somatostatin analog. So far, there has been no report of SSA leading to hyperthermia and pancytopenia, which we thought might be a kind of severe adverse effect of SSAs from our patient. Honestly, as for pancytopenia, we thought that might be related to the heart problem or hyperthyroidism before the medical therapy. But the pancytopeniagot worse immediately after the injection ofSSA, which cannot be explained by the heart problem or hyperthyroidism. The bone marrow biopsy suggested normal myeloproliferation. There was no evidence of any infection. Meanwhile, after the anti-allergy treatment with glucocorticoids, the patient's body temperature returned to normal and pancytopenia improved. Overall, allergic reaction of SSA was highly suspected. Additionally, there was a case report of TSH-secreting pituitary adenoma combined with Evans' syndrome in 2015. The report suggested that an excess of thyroid hormone itself promotes autoimmunity in Evans' syndrome [14]. So, we also suspected that our patient's pancytopenia might be caused by autoimmune response partly.

Because of the side effect of SSA, after the surgery and radiotherapy, the patient was treated with dopamine agonists (bromocriptine followed by cabergoline) to control the hyperthyroidism instead, which received a good efficacy. Medical treatment with dopamine agonists is a cornerstone of prolactinsecreting tumors, which have also demonstrated some efficacy in patients with GH- and TSH secreting adenomas recently [15].

In addition, the patient did a gene test, and we found the presence of variants of phosphodiesterase type 11A (PDE11A) gene. Immunohistochemistry revealed PDE11A expression is higher in somatotropinomas than in normal somatotrophs. But, the normal expression of the enzyme in most tumor tissues together with the lack of significant clinical phenotype suggests that these variants might only marginally contribute to the development of somatotropinomas [16].

\section{Conclusions}

TSH- and GH- secreting pituitary adenomas are rare. It is important to evaluate thyroid function to patient with heart problems and check pituitary imaging to the patient with hyperthyroidism and a normal (non-sup pressed) TSH. Surgical resection is the first-line treatment for both TSH and GHsecreting pituitary adenomas. Pre-operative medical therapy with somatostatin analogues (SSA) can reduce tumor size and control thyroid hormone and GH hypersecretion. But our patient's response to SSA treatment was limited. In our case, the patient presented rare and severe side effects of SSA, hyperthermia and pancytopenia, which seemed like a kind of allergic reaction. Dopamine agonists also have some benefits as maintenance therapy for postoperative TSH- and GH- secreting pituitary adenomas. Genetically, variants of phosphodiesterase type 11A (PDE11A) gene were observed in our patient, but these variants might only have marginal contributions to the development of somatotropinomas.

\section{Acknowledgement}

The authors thank Dr. Mei Peng from Hangzhou Veritas Genetics Medical Institute Co., Ltd. for helping us analysis the gene test of our patient.

\section{References}

1. Beck Peccoz P, Brucker Davis F, Persani L, Smallridge RC, Weintraub BD (1996) Thyrotropin-secreting pituitary tumors. Endocr Rev 17(6): 610638.

2. Skoric T, Korsić M, Zarković K, Plavsić V, Besenski N, et al. (1999) Clinical and morphological features of undifferentiated monomorphous GH/ TSH-secreting pituitary adenoma. Eur J Endocrinol 140(6): 528-537.

3. Colao A (2015) Treatment of pituitary tumours in 2014: Advances in therapy of adenomas secreting GH, ACTH and TSH. Nat Rev Endocrinol 11(2): 73-74.

4. Gatto F, Grasso LF, Nazzari E, Cuny T, Anania P, et al. (2015) Clinical outcome and evidence of high rate post-surgical anterior hypopituitarism in a cohort of TSH-secreting adenoma patients: Might somatostatin analogs have a role as first-line therapy? Pituitary 18(5): 583-591.

5. Gammage MD, Parle JV, Holder RL, Roberts LM, Hobbs FD, et al. (2007) Association between serum free thyroxine concentration and atrial fibrillation. Arch Intern Med 167(9): 928-934.

6. Socin HV, Chanson P, Delemer B, Tabarin A, Rohmer V, et al. (2003) The changing spectrum of TSH-secreting pituitary adenomas: diagnosis and management in 43 patients. Eur J Endocrinol 148(4): 433-442.

7. George JT, Jonathan C Thow, Bruce Matthews, Maurice P Pye, Vijay Jayagopal (2008) Atrial fibrillation associated with a thyroid stimulating hormone-secreting adenoma of the pituitary gland leading to a presentation of acute cardiac decompensation: a case report. J Med Case Rep 2: 67. 
8. Fukuhara N, Horiguchi K, Nishioka H, Suzuki H, Takeshita A, et al (2015) Short-term preoperative octreotide treatment for TSH-secreting pituitary adenoma. Endocr J 62(1): 21-27.

9. Colao A, Auriemma RS, Galdiero M, Lombardi G, Pivonello R (2009) Effects of initial therapy for five years with somatostatin analogs for acromegaly on growth hormone and insulin-like growth factor-I levels, tumor shrinkage, and cardiovascular disease: a prospective study. J Clin Endocrinol Metab 94(10): 3746-3756.

10. Cuevas Ramos D, M Fleseriu (2016) Pasireotide: a novel treatment for patients with acromegaly. Drug Des Devel Ther 10: 227-239.

11. Horiguchi K, Yamada M, Umezawa R, Satoh T, Hashimoto K, et al. (2007) Somatostatin receptor subtypes mRNA in TSH-secreting pituitary adenomas: a case showing a dramatic reduction in tumor size during short octreotide treatment. Endocr J 54(3): 371-378.

12. Tritos NA, BM Biller (2017) Pegvisomant: a growth hormone receptor antagonist used in the treatment of acromegaly. Pituitary 20(1): 129135.
13. Gariani K, P Meyer, J Philippe (2013) Implications of Somatostatin Analogues in the Treatment of Acromegaly. Eur Endocrinol 9(2): 132135.

14. Yasuda A, Oki M, Takagi A, Inomoto C, Nakamura N, et al. (2015) A Case of a TSH-secreting Pituitary Adenoma Associated with Evans' Syndrome. Tokai J Exp Clin Med 40(2): 44-50.

15. Colao A, Filippella M, Pivonello R, Di Somma C, Faggiano A, et al. (2007) Combined therapy of somatostatin analogues and dopamine agonists in the treatment of pituitary tumours. Eur J Endocrinol 156(Suppl 1): S57-S63.

16. Peverelli E, Ermetici F, Filopanti M, Elli FM, Ronchi CL, et al. (2009) Analysis of genetic variants of phosphodiesterase $11 \mathrm{~A}$ in acromegalic patients. Eur J Endocrinol 161(5): 687-694 